Divan Edebiyatı Araştırmaları Dergisi 12, İstanbul 2014, 13-28.

\section{FATMA BÜYÜKKARCI YILMAZ}

\title{
Divan Edebiyatında Nakş ve Nakkaş 1: İlk Yüzyıllar
}

\author{
Nakş and Nakkaş in Divan Literature 1: First Era
}

Ö Z E T

Maniheizm dininin kurucusu Mani, să̆lı̆̆ında öğretilerini Erjeng adl kitabında yazıya geçirmiş ve kitabının bir bölümünü kâinatı tasvir eden çizimlerle süslemiştir. Bu resimler çok güzel olduğu için bu kitap, gökten inen bir mucize olarak gösterilmiş ve bundan dolayı da Mani'ye nakkaşlık isnad edilmiştir. Yedi yazıt ve bir resim bölümünden oluşan bu resimli mecmua Nigâr, Nigâristan, Engelyûn veya Erteng adlarıyla da bilinir.

Divan edebiyatında da nakş, nakkaş ve ilgili dĭğer kelime ve terimler (musavvir, nigâr, Mani ve Erjeng gibi) kullanılarak çeşitli oyunlar ve edebi sanatlar vasitasıyla sevgilinin güzelliğinden, onun hayalinin aşı̆̆ın gönlüne nakşedilmiş olmasından, Allah'ın yaratıcilı vasfindan bahsedilmiştir. Bu kelime ve terimlerin divan şiirinde nasıl kullanıldığın tespit etmek amacıyla dönem bakımından da sinırlamaya gidilerek XIV. ve XV. yüzyıllardan dört şair seçilmiş ve divanları taranmıştır. Bu şairler Kadı Burhaneddin (ö. 800/1398), Şeyĥ̂ (ö. 832/1429'dan sonra), Ahmed Paşa (ö. 902/1497) ve Necati Beg (ö. 914/1509)'dir. Böylece divan edebiyatının gelişmeye başladiğı bu yüzyillarda bu kelime ve terimlerin hangi bă̆lamlarda kullanıldı̆̆ı ortaya konmaya çalışılacaktır.

A N A H T A R K E L İ M E L E R

Mani, Erjeng, nakş, nakkaş, Kadı Burhaneddin, Şeyhî, Ahmed Paşa, Necati Beg

\section{A B S T R A C T}

Mani, the founder of Manichaeism, in his lifetime wrote his teachings in a book called "Erjeng" and he ornamented a chapter of his book with drawings describing the universe. Since drawings in "Erjeng" are so beautiful, the book was shown as a miracle coming from the sky and therefore Mani was attributed to be a miniaturist. That illustrated periodical which consists of seven inscriptions and an illustration chapter is also known as "Nigâr", "Nigâristan", "Engelyûn" or "Erteng".

Also within the divan literature, the beauty of the lover, her image being engraved into the lover's heart and creativity attribute of Allah were mentioned through various literary arts by using the miniature (nakş), the miniaturist (nakkass), and other related words and terms (musavvir, nigâr, Mani, and Erjeng). In order to determine how these words and terms were used in divan poetry, limiting the search in terms of the era, four poets from XIV. and XV. centuries were selected and their poems were analyzed. Those poets are Kadı Burhaneddin (d. 800/1398), Şeyhî (d. later than 832/1429), Ahmed Paşa (d. 902/1497), and Necati Beg (d. 914/1509). In this way, it is tried to manifest in which context these words and terms were used in these centuries when the divan literature started to develop.

\section{K E Y W O R D S}

Mani, Erjeng, nakş (miniature), nakkaş (miniaturist), Kadı Burhaneddin, Şeyhî, Ahmed Paşa, Necati Beg

* Doç. Dr., Boğaziçi Üniversitesi Fen-Edebiyat Fakültesi, Türk Dili ve Edebiyatı Bölümü, İstanbul (yilmazfa@boun.edu.tr).

** Bu makale 1996 yılında sunulan bildirinin gözden geçirilmiş ve genişletilmiş şeklidir: "Divan Edebiyatında Nakş ve Nakkaş", Yazıdan Söze Edebiyat Sohbetleri, Boğaziçi Üniversitesi, 1996. 


\section{Giriş}

Miladi 216'da Güney Mezopotamya'da doğan, 276'da İran'da öldürülen Mani, Hristiyanlığın da etkisiyle Zerdüsst dinindeki gibi dualizme, yani iki kuvvetin âleme hâkimiyetine inanan ve "Maniheizm" adı verilen bir din ortaya koymuştur. Bu kuvvetlerden biri işığın temsil ettiği iyilik kudreti, diğeri ise karanlığın temsil ettiği kötülük kudretidir. Bu din, İran, Hindistan, Tibet, Çin ve Türkistan'da oldukça yayılmış ve XI. yüzyılda buralarda büyük bir gelişme göstermiştir. Uygur hükümdarı Bögü Kağan 762-63 yıllarında Maniheizmi kabul etmiş ve Mani rahiplerini Uygur idaresindeki Doğu Türkistan'a yerleştirmiştir. Mani'nin ölümünden sonra öğrencileri onun misyonunu devam ettirmiştir. Mani, sağlığında öğretilerini Erjeng adlı kitabında yazıya geçirmiş ve bu kutsal kitabın bir bölümünü kâinatı tasvir eden çizimlerle süslemiştir. Bundan dolayı Mani dininin başlıca sanatı kitap resmidir. Mani dinine mensup Türk sanatkârları, Uygur hükümdar sülâlesinin koruması altında ve onların teşvikiyle, ayrıca Mani'nin Erjeng adlı eserinde kâinatı temsil eden emsalsiz ressamlığının etkisiyle pek çok eser vermişlerdir (Arseven 1950: 1279; Gündüz 2003: 575).

Mani dininin Orta Asya üzerinden Çin'e ulaşması ise, bir elçinin 719'da Çin'e gitmesi ve Mani dinini öğretmesi ile gerçekleşmiştir. Uygur Hakanlığı 840'ta Kırgızlar tarafından ortadan kaldırılmış ve Uygurlar daha güneyde, Doğu Türkistan ve Kansu'da bulunan illere göç etmişlerdir (Esin 1978: 133-34; Esin 1972a: 201-02; Esin 1946: 250-60; Ligeti 1946:250-60). O devirlerde Çin, bugünkü Çin'den başka Orkun ve Uygur illerini ve hatta Kaşgar'ı da kaplıyordu. Kaşgarî̀ye göre Kaşgar ile Talas arasındaki bütün Türklere Çiğil denirdi. Demek ki Çin kelimesinin işaret ettiği bölge, İslam âleminde gayr-ı Müslim Türk sanatı etkilerini taşımıştır. İslam edebiyatında Çin ile beraber Çiğil ve Hoten eserlerinden de bahsedilir. Nigâr-hane-i Çin denen, aslında Manihai eserlerin bulunduğu yerin Çiğil memleketinde olduğu belirtilir (Esin 1972b: 334-35). Uygur etkileri Gazneliler devrinde İslam âlemine girmeye başlamış ve Cengiz istilasından sonra Türkistan ve İran'da artmıştır. İranlılar eski minyatürlerine "kâr-ı Çinî" diyorlardı ve resim koleksiyonlarını ifade 
etmek üzere "Nigârhane-i Çin" tabirini kullanıyorlardı (Ülken 1948: 51415).

İnsan ve manzara resimlerine suret, bunları tasvir edenlere musavvir denir. Musavvir, kitap resmi, yani minyatür yapan sanatkârdır. Gerek boyalı geleneksel kitap resmi, gerekse karakalem (kalem-i siyahî) ve fırça veya kalemle mürekkep kullanılarak yapılan resimlerin hepsini musavvir yapar. Musavvirler ikiye ayrılır; insan resmi yapanlara "sûretkârî", orman hayvanları ve hayvan mücadelesi tasvir eden resimleri yapanlara "cânversazî" denir. Sûretkârî resim, doğrudan doğa gözlemlenerek yapılır, gözlemler sonucu dimağda oluşan hayaller resme aktarılır. Hiçbir zaman eskiler kopya edilmez. Cânversâzî resim yapılırken ise sanatkârın kendi gözlemleri yerine eski ustaların koyduğu prensiplere uyulur, hayaller bir tarafa bırakılır (Dickson ve Welch 1981: 26061, 264-65).

Mani dininin kutsal kitabındaki resimler çok güzel olduğu için bu kitap, gökten inen bir mucize olarak gösterilir. Bundan dolayı da Mani'ye nakkaşlık isnad edilir. Yedi yazıt ve bir resim bölümünden oluşan bu resimli mecmua Nigâr, Nigâristan, Engelyûn, Erteng veya Erjeng adlarıyla bilinir. Divan edebiyatında da resme çeşitli şekillerde değinilmiş, nakş, nakkaş ve ilgili diğer kelime ve terimler (musavvir, nigâr, Mani ve Erjeng gibi) kullanılarak çeşitli oyunlar ve edebi sanatlar vasıtasıyla sevgilinin güzelliğinden, onun hayalinin aşığın gönlüne nakşedilmiş olmasından, Allah'ın yaratıcılık vasfından bahsedilmiştir. Divan edebiyatında sevgilinin güzelliğinden bahsedilirken teşbih ve telmih yoluyla kullanılan Erjeng, çok sözü edilmiş bir imajdır.

Nigâr, tasvir ve suret manasınadır. Resim gibi güzel sevgilidir. Mani'nin resim mecmuasına da Nigâr dendiği için şiirde buna da telmih vardır. Eskiden insan suretleri ve portreler yapan ressam ve musavvirlere "nigârende" veya "nigârî" denirdi. "Nigârhane" veya "nigâristan" da resim ve tasvir yapanların çalıştıkları yerlere ve duvarlarına resimler asılmış olan odalara, puthanelere denirdi. Eski saraylarda böyle nigârhaneler vardı. Bu gibi yerler için "nigârhane-i Çin, nigâristan-1 Çin, nigârhane-i Keşmir" terimleri de kullanılırdı. Sûdî’nin Gülistan şerhinde belirttiğine göre "Çin nigârhanesi" büyük bir kilisedir, üstad nakkaşlar en güzel nakışlarını oraya yapmışlardır. Ayrıca Nigârhane, Mani'nin re- 
sim mecmuasının diğer adıdır. Güzelleri çok olan yer anlamındaki nigârhane, divan şiirinde sevgilinin yanağı yerine de kullanılır.

Gerek el yazması kitaplara renkli olarak yapılan tezyinî resimlere ve gerekse şimdi minyatür dediğimiz renkli manzara ve insan resimlerine "nakş", bunları yapan sanatkârlara "nakkaş" denir. Yani nakkaş, her türlü nakış deseni, tezhip ve minyatür yapan sanatkârlar için kullanılan genel bir terimdir. Nakş kelimesinin yazı anlamına kullanıldığı da olur. Gökyüzü, cennet ve dünyanın görünümü de birer nakştır. "Nakkaş" ve "musavvir" ayrıca Allah'ın sifatlarındandır. "Musavver" ise suret verilmiş, tersim edilmiş anlamındadır.

Mecazen hile ve renk anlamlarına da gelen nakş kelimesi edebiyatta, "nakş geçmek" ve "nakş oynamak" deyimleri ile oyun, hile yapmak; "nakş bağlamak" deyimi ile halk ve tasvir eylemek, tasavvur ve tahayyül etmek anlamında kullanılmıştır.

Nakş, nakkaş ve ilgili diğer kelime ve terimlerin divan şiirinde nasıl kullanıldığını tespit etmek amacıyla dönem bakımından da sınırlamaya gidilerek XIV. ve XV. yüzyıllardan dört şair seçilmiş ve divanları taranmıştır. Bu şairler Kadı Burhaneddin (ö. 800/1398), Şeyhî (ö. 832/1429'dan sonra), Ahmed Paşa (ö. 902/1497), Necati Beg (ö. 914/1509)'dir. Böylece divan edebiyatının gelişmeye başladığı bu yüzyıllarda bu kelime ve terimlerin hangi bağlamlarda kullanıldığı ortaya konmaya çalışılacaktır.

\section{Divan Edebiyatında}

Nakkaşın, hayalindekileri resme aktardığını belirtmiştik. Divan edebiyatında da şair, sevgilinin hayalini bir nakkaş gibi gözüne veya gönlüne nakş eder. Çin ülkesi, Mani dininin yaygın olduğu bir yerdir. Mani'nin bir nakkaş, kitabının çok güzel resimlerle süslü olması ilgileri nedeniyle divan şiirinde güzel yüz, Çin'e benzetilir. Eskiden Çin ülkesinde Türklerin, özellikle Hita, Hoten, Maçin diyarının halkı ve güzellikleriyle meşhur olan Çiğil güzellerinin de bulunması kelimenin çok kullanılmasını sağlamıştır. Çin kelimesiyle birlikte "büt, nigâr, nakş, suret" gibi resimle ilgili kelimeler de sık sık kullanılır. 
Sevgilinin göz ve kirpikleri aşığın gönlüne açtığı yaralar, ayrıca kan1 olmaları nedeniyle birer nakkaştır. Saçı da yüz üzerinde değişik şekillerde duruşu ile nakkaşı andırır ve Mani'ye benzetilir. Divan şiirinde sevgilinin saçı, ayva tüyleri ve benlerle dolu olan yüzü ise bir nakş sayılir.

\section{Sevgilinin hayalinin göze (göze/yaşlı göze/suya) nakş olması}

Sûretkârîlerin, resim yaparken gözlemleri sonucu oluşan hayalleri resme aktardıklarını söylemiştik. Bu durum şiire aşığın, sevgilinin hayalini gözüne (göze/yaşlı göze/suya) veya gönlüne nakş etmesi, dolayısıyla sevgilinin her zaman gözünün önünde veya gönlünde olması şeklinde yansır. Sevgilinin yüzü, yanağı, dudağı, dişi, yani tüm güzellik unsurları göz yoluyla nakşedilir. Ahmed Paşa "Sanki bir nigârın nakşını mercan kadehe işler gibi, hayalini gözümde resm etmişim" der:

Resm itmişem gözümde hayâlüni gûyiyâ

Nakş-1 nigârı sâgar-1 mercâna yazmışam (G. 199/4)

Kadı Burhaneddin, "Senin güzelliğinin hayali gözde sanki su üzerine resmedilmiş nakştır" diyerek sevgilinin hayalinin yaşlı gözlerinde nakşedilmiş olduğunu belirtir:

Gözde hayâli hüsnünün nakş-1 ber-âbdur begüm

Gönülünüzde hattunuz yazdı cefâyı der-hacer (G. 554/3)

Kadı Burhaneddin bir başka beytinde, "Sevgilinin güzelliğinin nakşı gözümde hayal bağladı", dedikten sonra sevgilinin taş yürekli olduğuna da işaret eder:

Nakş-1 cemâli dilberün gözde hayâl bagladı

Gönüline mahabbetim nakş-1 hacer degül midür (G. 22/2)

Kadı Burhaneddin sevgiliye seslenerek "Sen beni kendinden uzak sanma, çünkü nerede olursan ol, senin nakşın gözümde resmedilmiş durumdadır" der: 
Sen bini özünden sanemâ sanma ırah çün

Nakşun gözüme kandayise ola musavver (G. 1146/6)

Yine Kadı Burhaneddin, "Gözümün önünde duran sen misin, yoksa hayalin mi, bilmiyorum" diyerek sanki her an sevgiliyi karşısında gördüğünü belirtir:

Bilimezüz ki sensin ya hayâlün

Olan gözümüze karşu musavver (G. 508/5)

Kadı Burhaneddin, nakş kelimesini hayal yerine kullanarak ansızın sevgilinin nakşının gözünün önüne geldiğini ve "senin derdine derman benim" dediğini söyler:

Zarûret hâline bahdum u nâgeh gözüme nakş1

İre geldi vü aydur ki senün derdüne dermânam (G. 1098/4)

Aynı hayale Şeyhî'de de rastlarız, "Sevgilinin hayali aniden gözüme musavver oldu, gözümde canlandı":

Nâgeh musavver oldu gözüme hayâl-i yâr

Takrî́ ile itâb kılıp eyledi hitâb (K. 12/8)

\section{Sevgilinin hayalinin gönle nakş olması}

Kadı Burhaneddin put gibi güzel sevgilisine seslenerek "Nakkaşlar çoktur ama hiçbiri senin güzelliğini gönlümdeki nakıştan daha güzel yapamaz",

Nakkâş çoh gele sanemâ lîk hüsnüni

Cân dilde nakş kılduğını yaza benzemez (G. 1058/5)

diyerek hiçbir nakkaşın sevgilinin güzelliğini kendi gönlündeki gibi resmedemeyeceğini; ayrıca "nakkaş onun benleri gibi ben yapamadı" (467/1) diyerek sevgilinin beninin resmedilemeyecek kadar güzel olduğunu ve hiçbir nakkaşın bu kadar güzel bir ben yapamayacağını söyler. Bir beytinde bu açıkça şöyle ifade edilir. "Onun güzelliğinin nakşı dünyada ortaya çıktığından beri nakkaşlar 'en güzel nakşı ben yaparım' diye davaya girişemez oldular": 
Olalı hüsni nakşı dünyâda fâş

Dahı da'vî kılımaz oldı nakkâş (G. 438/1)

Burada en güzel nakşı ancak Allah'ın yapacağı da düşünülmelidir. Kadı Burhaneddin sevgiliyi yüreğine nakşettiğini şöyle belirtir: "Bıçak alıp yüreğimi yararsam senin nakşını bulurum":

Yüregümde hem yine nakşun bulam

Bıçağ alıban anı yarar isem (T. 1450)

Necati nakkaşların, "Biz senin güzelliğini hercayi, yani daldan dala uçan gönüle nakş etmişiz, biz öyle nakkaşlarız ki akar suya bile nakş yapabiliriz" diyerek ayrıca şairlerin, nakkaşlar gibi güzel şiir yazdıklarını da vurgular:

Hercâyî dile eylemişüz hüsnüni tasvîr

Akar suya nakş idici nakkâşlaruz biz (G. 232/2)

\section{Sevgilinin güzellik unsurları ve nakş - nakkaş}

Sevgilinin güzellik unsurlarından "hat" ve "saç" nakkaş, "kirpik" kıl kalem, ayva tüyleri, saç ve dolayısıyla yüz Erjeng'e benzetilir.

Necatî'ni hayalindeki güzel, servi boylu, gonca dudaklı, kulak memesi gümüştendir. Necati musavvire seslenir ve "Eğer o yari tasvir edersen servi boylu, gonca dudaklı, kulak memesi gümüşten olsun" diyerek sevdiğini hayalindeki gibi resmetmesini ister:

Ey musavvir eger ol yârı idersen tasvîr

Serv-kad gonce-dehen sîm-benâgûş olsun (G. 430/3)

Yine Necatî put gibi güzel sevgiliye seslenerek onun nakkaşlıkta çok ünlü ve maharetli olan Çin musavvirlerince bile örnek alındığını söyler:

Korkaram kim lebünün örnegin alup sanemâ

Çîn musavvirleri bir sûret ile cân yazalar (G. 206/3) 


\section{Hat - Nakkaş}

Ahmed Paşa, ayva tüylerinin yanağı süslemekte usta olduklarını şöyle anlatır: "Ey hat! Rüzgâr nasıl çimeni su yüzüne (serperek) nakş ederse sen de yanağı nakş etmekte üstadsın":

Rûy-i âba sebzeyi nice ki nakş eylerse bâd

Ârızı nakşında ey hat sen dahi üstâdsın (G. 249/3)

\section{Saç - Nakkaş}

Ahmed Paşa sevgilinin güzelliğinden bahsederken "Zülf nakkaşı suya öyle bir resim yapar ki Çin Mani'sinin yazdığı Nigâristan'ın nakışları bile bu resmi kıskanır" der:

Zülfi nakkâşı suya bir resm ider kim reşk ider

Mânî-i Çîn yazdugı nakş-1 Nigâristân ana (G. 2/7)

Ahmed Paşa "Gözüm saçındayken senin dudağının nakşını hayal eder, çünkü saçın güya cevherlerle işlenmiş kadehi işleyen Çin nakkaş1dır", der. La'l kırmızı ve değerli oluşuyla bir cevheri, şekli nedeniyle de kadehi andırır. Saçın nakkaş olduğunu belirtmiştik. Saç öyle bir şekil almıştır ki sanki dudak resmi çizmektedir:

La'linün nakşın hayâl eyler saçındayken gözüm

Gûyiyâ nakkâş-1 Çîn'dir cevherî sâgar yazar (G. 66/6)

Yine Ahmed Paşa "Onun zülfü öyle bir nakkaştır ki suya Çin nakşı yazıp Mani'yi mat etti" diyerek zülfün Mani'den üstün bir nakkaş olduğunu belirtir:

Zülfi şol nakkâşdur kim suya nakş-i Çîn yazub

Mânîyi mât eyledi bir berg-i müşg-âgîn salub (G. 13/5)

Necati, sevgilinin yanağının letafetten su gibi titrediğini, bu yüzden kara saçının yanağı üstüne nakş olamadığını anlatır:

Su gibi ditrer letâfetde nigârâ ârızun

Anun içün nakş olımaz hatt-1 müşgîn üstine (G. 543/5) 


\section{Kirpik - Kil kalem}

Kadı Burhaneddin "La'1 ve dürrünün, yani dudak ve dişlerinin nakşını gözüm kıl kalem ile yazdı" der ve kirpikleri kıl kaleme benzetir:

La'1 ü dür nakşını kıl kalem ile yazdı gözüm

Zer varak üzre yine zî-leb ü dendân yazmış (G. 601/6)

Yine Ahmed Paşa'nın bir beytinde de kıl kalem kullanılır: "Kirpiğim yanağının hayalini o kadar güzel resmetti ki nakkaşlar onu kıl kalemle resmedemezler". Sevgilinin hayali kirpikler vasıtasıyla göze nakş ediliyor ve kirpik nakkaştan üstün tutuluyor:

Kirpügüm haddün hayâlin şöyle rengîn yazdı kim

Kıl kalemle resm idimezler anı nakkâşlar (G. 86/3)

Necati "Nakkaşlar, sen Çinli çocuğun zülfünün kıvrımını gördüklerinden beri kıl kalemlerini el ucuyla tutarlar" diyerek saç ve kıl arasında ilişki kurar. Saç, sevgilinin yanağında nakkaşların yaptığından daha güzel bir resim oluşturmuştur:

Çîn-i zülfini görelden sen Hitâyî-beççenün

Kıl kalemlerin el ucı ile tutar nakkâşlar (G. 123/2)

\section{Ayva tüyleri - Erjeng}

Ahmed Paşa sevgilinin yanağının nakşının Çin nigâristanını mat ettiğini, ay yüzlülerin sevgiliye nisbetle Erjeng suretinde olduklarını söyler. Yani sevgilinin yanağında ayva tüylerinin oluşturduğu nakış, Erjeng'den daha güzeldir:

Çîn nigâristânını nakş-1 ruhundur mât iden

Sana nisbet mâh-rûlar sûret-i Erjengîdür (G. 78/5)

Yanak parlaklığı, berraklığı ve şeffaflığı nedeniyle suyu andırır. Yüzün iki yanından sarkan saç lülelerinin yanak üzerinde çeşitli şekillerde duruşu ile adeta bir resim oluşur. Yanak zaten üzerindeki ayva tüylerinin oluşturduğu yazı ve resimler nedeniyle bir Nigâristan'dır. Şair bura- 
da sevgilinin saçının yanakta oluşturduğu resmi Mani'nin Erjeng adlı mecmuasılya kıyaslıyor ve ondan üstün tutuyor.

\section{Saç - Erjeng}

Ahmed Paşa "Sevgilinin mis kokulu saçı senin şiirin için Çin suretleri resmedilmiş hoş kokulu ve gönül bağlayıcı bir mecmuadır" diyerek, sevgilinin saçını Mani'nin çok güzel resimler içeren Erjeng adlı mecmuasina benzetir:

Şi'rün içün bir mu'anber dil-sitân mecmû'adur

Sûret-i Çînle musavver kâkül-i müşgîn-i dost (K. 19/32)

\section{Nakkaş - Allah}

Nakkaş-1 ezel, nakkaş-1 lem-yezel, nakkaş-1 sun‘ gibi tamlamalarla veya tek başına kullanılarak nakkaş kelimesi, Allah'ın yaratıcılık vasfına işaret eder. Bu kullanım Kadı Burhaneddin'de karşımıza çıkar, "Nakkaş1 ezel nakşının suretini yazalı beri bu dil ayaktan düştü ve bu göz elden gitti";

Nakkâş-1 ezel sûret-i nakşını yazaldan

Düşdi bu dil ayahdan u gitdi bu göz elden (G. 864/1)

"Sana nasıl kul olmayayım, çünkü nakkaş-1 ezel anber ile bir hatt-1 reyhan yazmiş olarak geldi":

Niçe kul olmayayım sana ki nakkâş-1 ezel

Geldi şol anber ile bir hat-1 reyhân yazmış (G. 640/3)

Necati'nin "Nakkaş-1 lem-yezeli özleyen, dilberin güzelliğini bahane eder" beytinde güzelin özelliklerinin aslında Allah'ın birer yansıması olduğuna vurgu yapılır:

Şol ki Nakkâş-1 lem-yezel özler

Dil-berün hüsnini bahâne eyler (G. 116/5) 
Ahmed Paşa'nın "Nakkaş-1 ezel cenneti o kadar yüceltti ki kapıların üstüne senin şerefli adını yazdı" dediği beytinde nakkaş kelimesi ile Allah'ın yaratıcılık vasfına değinilir:

Cenneti şol denlü ta'zîm itdi nakkâş-1 ezel

Kim senün nâm-1 şerîfün yazdı ebvâb üstine (K. 17/25)

Şeyhî de gönlüne seslenerek "Bu renk ve nakışı bırak da nakkaşa bak, onun cemalini gözle de kuşkuların ve gözündeki perde ortadan kalksin",

Gönlüm bu reng ü nakşı ko nakkâş̧a kıl nazar

Gözle yakîn cemâlini gitsin hicâb u zan (K. 7/22)

diyerek gerçeğin ancak maddi âlemden vazgeçmekle mümkün olacağını belirtir. Kadı Burhaneddin "Senin hayaline tapıyorum, ama putperest değilim, nereye bakarsam bakayım senin suretinin resmedilmiş musavver- olduğunu görüyorum",

Hayâlüne taparam büt-perest hod degülem

Nireye bahar isem sûretün musavver olan (G. 4/5)

şeklindeki beytinde sevgilinin canda veya dimağda resmedilmiş hayaline işaret eder. Bu hayal Allah'a kadar giderek kendinin O'ndan bir parça olduğuna da işaret eder. Şeyhî, "Musavvir-i ezel, yani Allah senin nakşını tasvir edeli beri Çin memleketinde bulunan suretler yüzünü toprağa sürer",

Musavvir-i ezel edeli nakşını tasvîr

Yüzünü hâke sürer Çîn içinde sûretler (G. 60/3)

dediği beytinde Allah'ın sevgiliyi çok güzel yarattığını ve artık Çin memleketinin güzelliğiyle meşhur olan suretlerinin yüzüne bile bakılmadığını belirtir.

\section{Nakş oynamak - Hile yapmak}

Şeyhî, "Put gibi bir güzel, ben saf gönüllüye öyle bir oyun oynadı ki gözüm bu yüzden o güzelin nakşına bakakalmıştır" diyerek nakş oynamak, yani oyun, hile yapmak deyimini kullanır ve aldandığını belirtir: 
Ben sâde-dile reng ile nakş oynadı bir büt

Bu nakş-1 nigâra gözüm andan nigerândır (G. 34/7)

\section{Nakş - Diğger}

Kadı Burhaneddin, gönlü bir ırmak gibi düşünerek onun aşk yüzünden taştığını ve bu derdi aktığı yatakta her taşa nakşedeceğini belirtir (ayrıca bkz. 465/1, 564/11, 626/1, 819/1). Burada taşa yapılan resmin hiç çıkmayacağı gerçeğine de işaret edilir:

Işk ile gönül seyl olıban taşa gerekdür

Nakş eyleye cân derdini her taşa gerekdir (G. 301/1)

Gönül, "Allah'ın nazar ettiği mahal, ilahî kemal ve cemalin en güzel tecelli ettiği yer"dir (Uludağ 2005: 107). "Dilerim ki gönlünde bu sevgi nakş olup taş üstüne kazılsın" diyerek Kadı Burhaneddin'in, ilahî aşkın gönlüne kazılmasını dilediğini söyleyebiliriz:

Dilerem gönülünde bu mahabbet

Ki nakş olup taş üsdinde kazıla (G. 544/6)

Şeyhî de "Nasıl mermerdeki nakşı sel ve yağmur çıkaramazsa çok ağlamam da hışmı gönlünden gidermedi" diyerek sevgilinin taş kalpliliğine ve taştaki resmin çıkmayacağına işaret eder:

Hışmı gönlünden gidermedi çok ağladıklarım

Seyl ü yağmurdan yuyulmaz nakş kim mermerdedir (G. 36/3)

\section{Sözle Nakş}

Yukarıdaki örneği burada tekrar verirsek Necatî, şairlerin maharetini överken "Biz öyle nakkaşlarız ki akar suya bile nakş yapabiliriz" der:

Hercâyî dile eylemişüz hüsnüni tasvîr

Akar suya nakş idici nakkâşlaruz biz (G. 232/2)

Aynı dönem şairlerinden Âhî (ö. 923/1517), "Şairler, gönüldeki sevgilinin nakşını o kadar güzel tasvir ediyorlar ki şimdi şiiri bırakıp nakkaş oldular" diyerek şairlerin sözle nakş yaptıklarını vurgular: 
Şol kadar tasvîr iderler dilde yârün nakşını

Şimdi şâirler kodılar şi' ri nakkâş oldılar (G. 22/4)

\section{Sonuç}

14-15. yüzyıl şairlerinden Kadı Burhaneddin, Şeyhî, Ahmed Paşa ve Necati Beg'in nakş, nakkaş ve ilgili kelime ve terimleri kullandıkları şiirleri göz önüne alırsak; öne çıkan kullanımlardan biri, sevgilinin hayalinin; yüz, yanak, dudak, diş gibi güzellik unsurlarının göz yoluyla ve kirpik marifetiyle göze, gözyaşlarına ve gönle nakşedilmesi motifidir. Bu şekilde sevgili her an aşı̆̆ın gözünün önünde veya gönlündedir. Sevgilinin göz ve kirpikleri, yüz üzerinde değişik şekillerde duruşu ile saçı da birer nakkaştır, Mani'ye benzetilirler. Divan şiirinde sevgilinin yanağı süsleyen saçı ve ayva tüyleri ve benlerle dolu yüzü bir nakş sayılır ve Erjeng'e benzetilir. Nakkaş-1 ezel, nakkaş-1 lem-yezel gibi tamlamalarla veya tek başına kullanılarak nakkaş kelimesiyle, Allah'ın yaratıcılık vasfına işaret edilir.

Bu dönemle ilgili olarak; özellikle sevgilinin güzellik unsurları ele alındığında, tasavvufi göndermeler akla gelse de öne çıkan unsurun tasavvufi olmadığı, divan edebiyatının genel hayal dünyasına uygun kullanımların yer aldığını görürüz. Özellikle Şeyhî, Ahmed Paşa ve Necatî'de durum böyleyken, bu şairler arasında hem ilim hem de devlet adamı olarak Kadı Burhaneddin'in ayrı bir yeri vardır. Tarlan onun için “...muasırlarının hiçbirine benzemiyordu. Ne tasavvufu büyük İran mutasavvıfları vadisinde mevizeler yazarak didaktik bir hale getirmiş, ne de derin bir vecd içinde onu sembolsüz halde terennüm etmişti." der ve hacimli divanın "yüzde sekseni bu hüviyettedir." diye ekler (Tarlan 1958: 9-10). Onun, nakş ve nakkaş bağlamında, sevgiliye ait güzellik unsurlarını tasavvufi göndermelerle de ele aldığı, tasavvufi söyleyişi benimsediği görülür. 


\section{Kaynaklar}

ARSEVEN, Celâ1 Esad (1950), "Mâniye veya maniheizm" Sanat Ansiklopedisi, c. III, İstanbul: Milli Eğitim Bakanlığı, s. 1279.

ARSEVEN, Celâl Esad (1950), "Musavvir", Sanat Ansiklopedisi, c. III, İstanbul: Milli Eğitim Bakanlığı, s. 1474.

ARSEVEN, Celâ1 Esad (1950), "Nigâr", Sanat Ansiklopedisi, c. III, İstanbul: Milli Eğitim Bakanlığı, s. 1502.

ARSEVEN, Celâl Esad (1950), "Nigârende", Sanat Ansiklopedisi, c. III, İstanbul: Milli Eğitim Bakanlığı, s. 1502.

ARSEVEN, Celâl Esad (1950), "Nigârhane", Sanat Ansiklopedisi, c. III, İstanbul: Milli Eğitim Bakanlığı, s. 1503.

ARSEVEN, Celâ1 Esad (1950), "Nakış", Sanat Ansiklopedisi, c. III, İstanbul: Milli Eğitim Bakanlığı, s. 1496.

ARSEVEN, Celâl Esad, "Nakkaş", Sanat Ansiklopedisi, c. III, İstanbul: Milli Eğitim Bakanlığı, s. 1497.

BÜYÜKKARCI, Fatma (1996), "Divan Edebiyatında Nakş ve Nakkaş", Yazıdan Söze Edebiyat Sohbetleri, Boğaziçi Üniversitesi, 1996.

ÇAVUŞOĞLU, Mehmed (1971), Necâtî Bey Divani’nın Tahlîli, İstanbul: Milli Eğitim Bakanlığ1.

ÇELTiK, Halil (haz.) (1998), Ömer Ferit Kâm ve Âsâr-ı Edebiye Tetkikatı, Ankara: Kültür Bakanlığ1.

DICKSON, Martin Bernard and Stuart Cary Welch (1981), The Hougliton Shahnameh, volume I, Cambridge: Harvard University.

ERGIN, Muharrem (1980), Kadı Burhaneddin Divanı, İstanbul: İstanbul Üniversitesi.

ESİN, Emel (1972), "Burkan ve Mânî Dinleri Çevresinde Türk San'atı", Türk Kültürü El-Kitabı Cilt II, Kısım Ia, İstanbul: Milli Eğitim Bakanlığı, s. 334-35.

ESİN, Emel (1972a), "İslâmiyetten Evvel Orta Asya Türk Resim San'atı," Türk Kültürü El-Kitabı, Cilt II, Kısım la, İstanbul: Milli Eğitim Bakanlığı, s. 201-02. 
ESİN, Emel (1978), “İslamiyetten Önceki Türk Kültür Tarihi ve İslama Giriş", Türk Kültürü El-Kitabl, II, Cild Ib'den Avrı Basım, İstanbul: Edebiyat Fakültesi, 133-34.

ESİN, Emel (1984), "Uygur Sanatı," Türk Ansiklopedisi, c. XXXIII, Ankara: Milli Eğitim Bakanlığı, s. 133.

GÜNDÜZ, Şinasi (2003), "Maniheizm", Türkiye Diyanet Vakfı İslâm Ansiklopedisi, c. 27, Ankara: Türkiye Diyanet Vakfı, s. 575-577.

İSEN, Mustafa ve Cemâl KURNAZ (1990), Şeyhî Divanı, Ankara: Akçağ.

LEVEND, Agâh Sırrı (1943), Divan Edebiyatı: Kelimeler ve Remizler Mazmunlar ve Mefhumlar, 2. bs., İstanbul: İnk1lâp Kitabevi.

LİGETİ, L. (1946), Bilinmeyen İç-Asya, çev. Sadrettin Karatay, İstanbul: Ankara Üniversitesi Dil ve Tarih-Coğrafya Fakültesi.

ONAY, Ahmet Talât (1992), Eski Türk Edebiyatında Mazmunlar, haz. Cemal Kurnaz, Ankara: Türkiye Diyanet Vakfı.

PALA, İskender (t.y.), Ansiklopedik Divân Şiiri Sözlü̈̆̈̈̈, Ankara: Akçağ.

SUNGUR, Necati (1994), Âĥ̂ Divânı, Ankara: Kültür Bakanlığı.

TARLAN, Ali Nihad (1966), Ahmed Paşa Divanı, İstanbul: Milli Eğitim Bakanllğ̆1.

TARLAN, Ali Nihad (1958), “Kadı Burhaneddin'de Tasavvuf (Bir Gazelinin Şerhi)", İÜ Edebiyat Fakültesi Türk Dili ve Edebiyatı Dergisi, cilt VIII, s. 8-15.

TARLAN, Ali Nihad (1959), “Kadı Burhaneddin'de Tasavvuf (İkinci Gazelinin Şerhi)", İÜ Edebiyat Fakültesi Türk Dili ve Edebiyatı Dergisi, cilt IX, s. 27-32.

TARLAN, Ali Nihad (1960), “Kadı Burhaneddin'de Tasavvuf III (Bir Gazelinin Şerhi)", İÜ Edebiyat Fakültesi Türk Dili ve Edebiyatı Dergisi, cilt X, s. 1-4.

TARLAN, Ali Nihad (1961), "Kad1 Burhaneddin'de Tasavvuf IV”, İÜ Edebiyat Fakültesi Türk Dili ve Edebiyatı Dergisi, cilt XI, s. 19-24.

TARLAN, Ali Nihad (1963), Necatî Beg Divanı, İstanbul: Milli Eğitim Bakanlığı.

[TARLAN], Ali Nihat (1934), Şeyhî Divanını Tetkik, İstanbul: İstanbul Üniversitesi, Edebiyat Fakültesi. 
TOLASA, Harun (1973), Ahmet Paşa'nın Şiir Dünyası, Ankara: Sevinç Matbaasi.

ULUDAĞ, Süleyman (2005), Tasavvuf Terimleri Sözlü̈̆̈̈̈, 2. bs. İstanbul: Kabalc1.

ÜLKEN, Hilmi Ziya (1948), İslam Sanatı, İstanbul: İstanbul Teknik Üniversitesi. 